\title{
The covid-19 Epidemic, China Containment Contexts and Risk Mitigation, Public Health Lessons Learned is it Feasible for Europe \& US
}

\author{
Hamid Yahya Hussain* \\ Professor, Dubai Health Authority, University of Baghdad, UAE
}

\section{SHORT COMMUNICATION}

Despite the high morbidity and mortality rates of COVID-19 infection china witnessed during the first two months of 2020, and compared to the short time of the epidemic among Wuhan city population in Hubei territory, the response of the health system to the disaster in this country was significantly effective, despite what seemed clear in the early days that the virus was fierce to the point of conquering the capabilities of the country, and it is so explosive, we all had the feeling that China was on the verge of complete collapse within few weeks.

The massive response of the health system in China was tremendous and built on two major strategies, recognizing that the existing battle is an existential battle for which all available energies were to be enrolled whatever losses happen, on the other hand, strict control and preventive public health measures applied through highest available protocols, standards and guidelines no matter what it costs of sacrifices, thus the response led aggressively by health system leadership along with political leadership. The measures and steps applied were quite radical and extremely through the following tactics:

\section{Rapid and Definite Diagnosis and Isolation of Covid-19 Cases}

In the case of the COVID-19 outbreak, it showed that within one week of identifying the unknown virus, China successfully sequenced it and reported the genetic information to the World Health Organization (WHO). Compared to other outbreaks e.g. SRRS 2003 which took a couple of months to be identified and sequenced out, while it took a few years when comes to HIV in the 1980s. It is obvious that identification of a virus's genetic sequence is decisive in developing medication, vaccine and testing kits. One of the critical tools in controlling a major epidemic is having specific, reliable, accurate and fast detection methods to screen infected and non-infected people. During the early days of the outbreak in Wuhan, there were no test kits available, and screening depended on laboratory nucleic acid sequencing analysis, a labor-intensive and costly method. The National Medical Products Administration of China took immediate action to speed up the work of biotech companies to develop detection kits. The first kit was introduced on 13 January, with a sufficient supply available two weeks later [1].

Applying 4 Rights Principles: Right Decisions, Right Time, Right Place and Right People

One of the significant strategic steps put in place in china's response is to listen carefully and follow the instructions of science and public health experts during pandemic events. China's unprecedented systematic and proactive risk management, based on collaboration between government officials and health experts, has proven to be effective in containing and controlling COVID-19. The timely release of disease-related clinical data to the public and WHO helped many around the world prepare for the spread. Thus, analyzing more than 40,000 cases in China, we know $80 \%$ of COVID-19 infected patients will not need medical intervention, while $20 \%$ would need medical treatment and care. China's health system response was the first to raise the risk management response to the highest level in the early days of the outbreak when there were no confirmed cases.

a) Communicating clear guidance about the degree and scope of lockdowns.

b) Ensuring rigors tracking down to individuals, apartments, houses, communities, organizations, public facilities, and city management.
Quick Response Code:

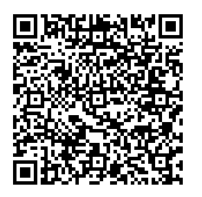

Address for correspondence: Hamid Yahya Hussain, Professor, Dubai Health Authority, University of Baghdad, UAE

Received: March 18, 2020

Published: March 30, 2020

How to cite this article: Hamid YH. The covid-19 Epidemic, China Containment Contexts and Risk Mitigation, Public Health Lessons Learned is it Feasible for Europe \& US. 2020 2(2) OAJBS.ID.000156. DOI: 10.38125/OAJBS.000156 
c) Offering essentials like food and supplies flowing through organized, government-controlled arrangements?

d) Developing new infectious disease care facilities and management centers to isolate monitor and treat positive cases.

e) Creating electronic recording and tracking systems and local response teams to handle identified cases $24 / 7$.

f) Initiating centralized reporting and communication channels to keep citizens informed.

g) Developing \&activating efficient outbreak information system: linking big data to epidemiological and clinical contexts of the outbreak

h) What was one of the cities to use big data and information technology in the prevention and control of COVID-19? They use "one map approach, one code, and one index." The following policies implemented:

i) Healthcare-related facilities could open first. Businesses reopened in several phases based on priorities

j) Codes for everyone in the city were established and everyone who entered the city. The green code allows you to move freely. The yellow code requires a seven-day self-quarantine. The red code requires a 14-day self-quarantine. The yellow and red codes can be turned green after the quarantine time.

k) Self-monitoring and recording temperature and update their profile daily.

l) Close Monitoring of health database Diseases Control and Prevention center.

These measures have so far proven to be very effective. While it is challenging to effectively detect travellers who might bring COVID-19 back to the city [2].

Pumping Maximum medical resources. Mobilizing national stocks and trained labor: China people showed courageous, solidarity and united in the effort to combat COVID-19. The lack of medical resources available at the time of immediate need was the main reason behind the high mortality rate in Wuhan. At first lack of disaster control management response mechanisms led to poor disease containment, and weeks of chaos. Yet In allocation and mobilization of resources was put in place in investigating cases, identifying close contacts, and making sure they remain under surveillance. In addition, doctors completed the world's first double-lung transplant surgery on a COVID-19 patient. The shortage of protective medical supplies and lack of knowledge about COVID-19 were the main factors causing a large number of healthcare workers to contract the virus in the early weeks of the outbreak in Wuhan. Over the past 6-8 weeks, however, 31 medical teams consisting of more than 42,000 doctors and nurses were sent to Wuhan to combat the outbreak. Two new hospitals with over 1,000 beds each were built in less than 10 days in Wuhan [3].

\section{Placing Rigorous Public Health Precautions (Control and Prevention Standards) in Communities, Schools, Businesses, Government Offices and Homes:}

In confronting COVID-19, everyone is sharing equal risk and responsibility. As COVID-19 is extremely contagious, it is more crucial to mobilize all of society and get everyone involved in the process. The key to success is to make everyone engaged in management, get every unit involved and hold officials accountable, and be responsive to new challenges. Careful planning and clear guidance are helpful. Many businesses, organizations, schools, and universities are successfully implementing computer-based online learning using technology like Zoom meetings, which could be models for future development. Large gatherings and multiple person-to-person contacts during an epidemic. China might have lost billions of dollars by essentially stopping all business, yet in the end, this will have been a wise decision and correct action [4]

\section{Maintaining Effective Public Health Communications}

Major lessons learned from China's response are providing clear and continuous, communication to the public. e.g. The major news outlet provides daily updates on the number of COVID-19 cases and clinical treatment outcomes, plans to be implemented and guidelines and procedures to follow. Public Health mobilization has been invested in fully from the beginning of the outbreak. Easyto-understand educational materials for students and the public with information about COVID-19 and how to prevent the spread [5].

\section{The Long Way Forward}

China experienced great loss in the current crisis estimated to be 60 billion USD; about 78\% of the total company's workforces in Hubei territory were somehow enforced to stay home and $50 \%$ at other territories, Yet China is restarting its economy, reopening schools and returning to normalcy. As a report from the WHOChina Joint Mission concluded, a science-based, risk-informed and phased approach is being taken, with a clear recognition of and readiness for the need to immediately react to any new COVID-19 cases or clusters while elements of the containment strategy are lifted. These are some lessons; the global community could learn from China at the national and local levels. This global health risk teaches us the importance of preparedness to prevent and control an infectious disease outbreak. It could also help us think about how to modernize disease control and prevention in China and around the world.

\section{CONCLUSION}

Initial readings of the COVID-19 outbreak in Europe and the United States of America indicate an accelerating and aggressively growing pattern, daily increasing the incidence of diseases and deaths alike, and the devastating paralysis of public life because of that. Europe and USA health systems' response looks weak in handling the events of the transmissions chain. The phenomenon of a steady expansion of outbreaks without showing signs of effective containment will put the whole world in complex scenarios not far from full of surprises about the ferocity of the virus and its superior capabilities to expand and spread.

\section{REFERENCES}

1. (2019) US Centers for Disease Control and Prevention. Coronavirus disease 2019 (COVID-19): situation summary.

2. Wu Z, McGoogan JM (2020) Characteristics of and important lessons from the coronavirus disease 2019 (COVID-19) outbreak in China. JAMA.

3. Jernigan DB (2020) Update: public health response to the coronavirus disease 2019 outbreak United States, February 2020. MMWR Morb Mortal Wkly Rep 69(8): 216-219.

4. Hellewell J, Abbott S, Gimma A (2020) Feasibility of controlling COVID-19 outbreaks by isolation of cases and contacts. Lancet Glob Health S2214109X (20): 30074-30077.

5. Bai Y, Yao L, Wei T (2020) Presumed asymptomatic carrier transmission of COVID-19. JAMA. 